\title{
Sequential Sampling of Adults and Nymphs of Euschistus heros (F) (Hemiptera: Pentatomidae) on Soybean Bt and Non-Bt
}

\author{
Paulo Rogério Beltramin da Fonseca ${ }^{1}$, Marcos Gino Fernandes ${ }^{2}$, Wagner Justiniano ${ }^{2}$, Leonardo Hiroito Cavada ${ }^{1} \&$ \\ João Alfredo Neto da Silva ${ }^{1}$ \\ ${ }^{1}$ Faculdade de Ciências Agrárias, Programa de Pós-Graduação em Agronomia (Produção Vegetal), Universidade \\ Federal da Grande Dourados, Dourados/MS, Brazil \\ ${ }^{2}$ Faculdade de Ciências Biológicas e Ambientais, Programa de Pós-Graduação em Entomologia e Conservação \\ da Biodiversidade, Universidade Federal da Grande Dourados, Dourados/MS, Brazil \\ Correspondence: Paulo Rogério Beltramin da Fonseca, Universidade Federal da Grande Dourados (UFGD), \\ Faculdade de Ciências Agrárias. Rodovia Dourados-Itahum, Km 12, Caixa Postal 533, Bairro Aeroporto, CEP: \\ 79804-970, Dourados/MS, Brazil. E-mail: prbeltramin@hotmail.com
}

Received: July 17, 2014 Accepted: August 31, 2014 Online Published: October 15, 2014

doi:10.5539/jas.v6n11p110 URL: http://dx.doi.org/10.5539/jas.v6n11p110

\begin{abstract}
To deploy the appropriate management of adults and nymphs of Euschistus heros (Fabricius, 1794) in soybean, we need to construct a sampling plan that allows estimate population density quickly and accurately. This research aimed to perform sequential sampling of adults and nymphs of E. heros in Bt and non-Bt soybeans. For the evaluations we used the method of cloth-to-hit, two regions in which the sample areas where we collected a sample randomly per plot of each trial were installed. Evaluations were performed at 7, 14, 21, 28, 35, 42, 49, 56, 63, 70, 77, 84, 91, 98 days after emergence (DAE). We adopted the model of contagious distribution, it was constructed a sequential sampling plan in accordance with the Sequential Probability Ratio Test (TSRP). The adopted control level two bugs (adults and nymphs) per cloth beat. The analysis showed two lines of decision: the upper, which is the condition that the adoption of a method of control is recommended, defined by $\mathrm{S} 1=$ $6.2449+0.14244 \mathrm{n}$; and below, representing that the adoption of some method of control is not recommended, defined by $\mathrm{S} 0=-6.2449+0.14244 \mathrm{n}$. The sampling showed a maximum expected number eight samples to determine the need or otherwise of control. For management based on economic injury level, the expected number of sample units is 17, indicated by the Sequential Probability Ratio Test Wald curve.
\end{abstract}

Keywords: Glycine max L., damage, sampling, horizontal dispersion

\section{Introduction}

Euschistus heros (Fabricius, 1794) (Hemiptera: Pentatomidae) is the most abundant and prevalent species in areas cultivated with soybeans in Brazil (Panizzi et al., 2012; Krinski et al., 2013) Bedbugs occur in soybean at all stages and are harmful from the beginning of pod formation until grain maturity (Zambiazzi et al., 2012). The damage caused by E. heros when uncontrolled can get up to $30 \%$ on soybean (Vivan \& Degrande, 2011).

The Bt soybean is a tool to be used in integrated pest management (IPM), with the goal of increasing plant resistance to insects (Roberts et al., 2010; Yu et al., 2011; Dutra et al., 2012; Fonseca et al., 2013). However, despite the great advances in $\mathrm{Bt}$ technology poses to world agriculture, their adoption in some regions may be affected positively or negatively, depending on the characteristics of each locality (Degrande \& Barros, 2012).

Thus, decision making in integrated pest management (IPM) follows protocols to decide on management action based on a review of the pest population level, in which the sampling plans are a crucial component of IPM, allowing an estimate pest, which will be taken into consideration to control or not control (Fernandes et al., 2011).

The same area can be sampled several times over a period of time, focusing on the same cycle of insect life (in which case the sampling period must match the chosen stage of life) (Kuno, 1991). These studies generally provide information on population dynamics in a particular area over the years, making it possible to correlate levels of population with certain soil and climatic factors (Kaplan \& Eubanks, 2002).

Sequential sampling has been shown to be faster and more reliable than conventional sampling and can minimize the research effort because the number of samples required depends on the size of the study population (Kogan 
\& Herzog, 1980). Intensive studies including continuous observation of a local population over a period of time. Typically, the information derived from these studies allow us to construct life tables, assessing levels of parasitism, dispersal rates, and changes in the population; they also help to determine the factors that drive and regulate large populations of insects (Qaim \& Zilberman, 2003).

Sequential sampling can be applied to agroecosystems and natural ecosystems, with possible use sequential sampling method for the rapid and accurate determination of the right to manage the pest targets and reducing the number of insecticide applications (Fernandes et al., 2003).

Sequential sampling plans can therefore be considered valuable tools when you already have basic knowledge about the populations of pests and their natural enemies, including studies on behavior and defining levels of control and security, among other requirements needed to develop these plans (Fernandes et al., 2002).

In this context, this study aimed to establish a sequential sampling plan for adults and nymphs Euschistus heros in $\mathrm{Bt}$ and non-Bt soybean into two regions under field conditions.

\section{Materials and Methods}

The experiment was conducted under field conditions in two experimental areas located at Farm Rincão Porã, the geographic coordinates $22^{\circ} 14^{\prime} 25^{\prime \prime} \mathrm{S}, 54^{\circ} 42^{\prime} 60.7^{\prime \prime} \mathrm{W}$ and altitude of $403 \mathrm{~m}$ in the town of Dourados and Farm Boa Sorte in the geographical coordinates $22^{\circ} 01^{\prime} 07^{\prime \prime} \mathrm{S}, 54^{\circ} 32^{\prime} 15^{\prime \prime} \mathrm{W}$ and altitude of $310 \mathrm{~m}$ in the municipality of Douradina during harvest 2011/2012. The soil of the area is classified as Typic Distroferric (RH) of loamy soil. The climate, according to Köppen's humid mesothermal, Cwa type, with annual average temperatures and precipitation ranging from $20^{\circ} \mathrm{C}$ to $24{ }^{\circ} \mathrm{C}$ and $1.250 \mathrm{~mm}$ to $1.500 \mathrm{~mm}$ (Fietz \& Fisch, 2006). For management of two experimental areas with soybean, we used the no-tillage system, and corn (Zea mays L.) as preceding crop. The area of this experiment was dried with glyphosate combined with mineral oil $\left(2.01 . \mathrm{ha}^{-1}+0.5\right.$ 1.ha $\left.\mathrm{h}^{-1}\right)$, respectively.

The seeds used were of Bt soybean AL 6910 Intact RR2 PROTM and non-Bt RR BMX Potencia ${ }^{\circledR}$, constituting the 2 treatments in two different locations. Sowing were performed in the experimental areas, the first area Farm Rincão Porã performed on 22/10/2011, Farm Boa Sorte second area performed on 29/10/2011, with a density of 15 seeds per meter, adopting a population of approximately 300.000 plants $^{-1} \mathrm{~h}^{-1}$. The row spacing was 0.50 meters. For fertilizer application in both cultivar was used $300 \mathrm{~kg} \mathrm{ha}^{-1}$ of NPK formulation $(2: 18: 18)$. We carried out the weed and disease control with application of herbicides, fungicides, and not the application of insecticides was carried out in the areas studied.

We evaluated the spatial distribution of adults and nymphs of the stink E. heros in two regions (Dourados and Douradina ) with two fields each containing 100 plots in each area, each plot consisted of 11 rows with $5 \mathrm{~m}$ long, totaling $\left(27.5 \mathrm{~m}^{2}\right)$ with soybean $\mathrm{Bt}$ and non Bt constituting the two treatments. The sampling methodology used was the method of cloth-to- beat, consisting of two sticks of wood connected by a white cloth, with a length of 1 $\mathrm{m}$ and width of $1.4 \mathrm{~m}$. For the samples, one end of cloth was placed between the rows of soybeans, being adjusted to the base of a row of plants and other plants extended over the adjacent row. The plants of a row $(0.50$ $\mathrm{m}^{2}$ ) were shaken vigorously in order to bring down the pest insects on the cloth (Sturmer et al., 2012). Samples were taken at 7, 14, 21, 28, 35, 42, 49, 56, 63, 70, 77, 84, 91, 98 days after emergence (DAE) in soybean Bt and non-Bt.

The level of action, from which the chemical control of bedbugs should be done, is four adult bed bugs or nymphs with more than $0.5 \mathrm{~cm}$, the mean of the observed sample Hoffmann-Campo et al. (2000).

However for the control of bed bugs based on biological control and integrated pest management, in this paper we adopted the control level two adult bugs and nymphs by cloth-to-beat. The lower than recommended for the chemical control based on the alternative to insecticides to control the pest slower responses control level was used, thus being necessary control action before the pest reaches the critical economic injury level. It is possible to monitor this level of infestation with sequential sampling of adult bugs and nymphs in all instars.

The data on the number of adults and nymphs were used for the mathematical description of the spatial dispersion of the population of this insect, which showed adequate fit to the Negative Binomial distribution (Fonseca et al., 2014).

The security level $(\mu 0)$ was adopted by $10 \%$, as is well below the level of damage, offering less possibility of incurring in Type I and Type II errors. O K common $(\mathrm{Kc})$ was determined by the method of Bliss and Owen (1958). The values used for the type I and II errors were $\alpha=0.05$ and $\beta=0.05$, respectively, because these values are the most appropriate to work with insects (Young \& Young, 1998). 
For data analysis, the sequential sampling plan constructed for the studied species, based on the Sequential Probability Ratio Test (TSRP), according to the methodology developed by Wald (1947). The purpose of the plan is to test with the smallest possible number of sample units, the hypothesis $\mathrm{H} 0$ versus $\mathrm{H} 1$, the rejection of $\mathrm{H} 0$ indicates the need for pest control, and its acceptance, the non-application of control methods.

Lines were constructed decision needed to perform the test TSRP. The top line indicates the decision, regardless of the number of these per plot the maximum value of the number of sampling units in the presence of adults and nymphs of bugs, so it is determined that the population of this pest has reached the proposed level of control; On the other hand, the lower line indicates the decision, regardless of the number, the minimum value of parcels with bedbugs from which one can safely say that the pest population is below the level of security, it is possible to conclude, therefore, you will not need to adopt any measure of control (Barbosa, 1992).

The top line of the test decision is defined as: $\mathrm{S} 1=\mathrm{Sn}+\mathrm{h} 1$. The line below is defined decision TSRV test as: S0 $=\mathrm{h} 0+\mathrm{Sn}$. The value $\mathrm{n}$ indicates the number of sampling units to be used for sampling. Each sample unit is a part. The values $\mathrm{h} 0, \mathrm{~h} 1$ and $\mathrm{S}$ were determined for aggregate spatial distribution represented by the Negative Binomial.

Thus, according to the model of the spatial distribution of the bug studied for the first observation using $\mathrm{n}$ equal to 1 and determines the value of the upper limit and lower limit for the sampling unit 1 ; the second observation using $\mathrm{n}$ equal to 2, determining, then the values of the upper and lower limits for the sample unit number 2 , and so on, until the last sampling unit required in the sampling plan.

The properties of a proposed sampling plan shall be known as much as possible before the implementation of the program. The evaluation of TSRP Wald test is generally based on the Operating Characteristic Curve - CO (m) and bow Size Expected Sampling Units - E (n). Therefore, after the construction of sequential sampling plan, it is important to determine the CO curve $(\mathrm{m})$, which is the graphical representation of the operative characteristic function that gives the probability of completion of sampling and not advise the control when the level of infestation pest in the crop is at or above the level of control adopted, or else advise the control when the infestation level is equal to or below the level of security adopted. Thus, this curve indicates the probability of adopting a correct or wrong for any level of infestation decision.

Have Expected size of the curve E (n) represents the average number of observations required to make the decision to perform or not control. The functions used for the determination of both curves in any type of spatial distribution are presented (Young \& Young, 1998).

\section{Results and Discussion}

To construct the sequential sampling plan for the number of adults and nymphs of $E$. heros, settled by adhesion test frequency that the Negative Binomial distribution is the model that describes the type of spatial distribution in the field with greater precision, according to the results obtained by Fonseca et al. (2014). The adopted control level of 2.0 bugs per cloth-to-beat (adults and nymphs). The security level $(\mu 0)$ was adopted in 1.0 , it is well below the level of damage, offering less possibility of incurring in Type I and Type II errors.

Due to rapid insect development (life cycle) sequential sampling within seven to seven days is essential to be observed before the fourth instar nymphs since at this stage the pest causes damage already. If the sample has a longer period of time runs the risk among a sample and the other to achieve a high level of infestation of nymphs and adults may cause damage to culture.

Monitoring for an alternative to chemical control should be initiated in the early development of culture and so the presence of the bug is observed, perform a control strategy, not to allow high infestation, taking into account the slower action of biological control.

Taking into account also that the soybean crop and cultivated in areas with large tracts, the sampling is fundamental to locate the presence of this pest in different locations of a property that already exists population dynamics of the same environment, as well as in different environments (Fonseca et al., 2014). Population dynamics and influenced by climatic conditions (rainfall, temperature) which is necessary to achieve constant sampling information accurately.

With the use of the common k obtained (3.0301) was constructed a plan of sequential sampling of adults and nymphs of E. heros in graphical form (Figure 1).

Therefore, to build the sequential sampling plan for the number of adults and nymphs of $E$. heros in $\mathrm{Bt}$ and non-Bt soybean, the hypotheses of interest are $\mathrm{H} 0: \mu=\mu 0=0.10 \mathrm{H} 1: \mu=\mu 1=0,20$.

Thus, the upper limit of the decision from which it is accepted H1: $\mu 1=0.20$ is: $\mathrm{S} 1=6.2449+0.14244 \mathrm{n}$. And 
the lower limit of decision to which it is accepted H0: $\mu 0=0.10$ is: $\mathrm{S} 0=-6.2449+0.14244 \mathrm{n}$. From the upper line $\mathrm{H} 0$ is rejected, that is, control, and below the lower accepts $\mathrm{H} 0$ is not controlled (Figure 1).

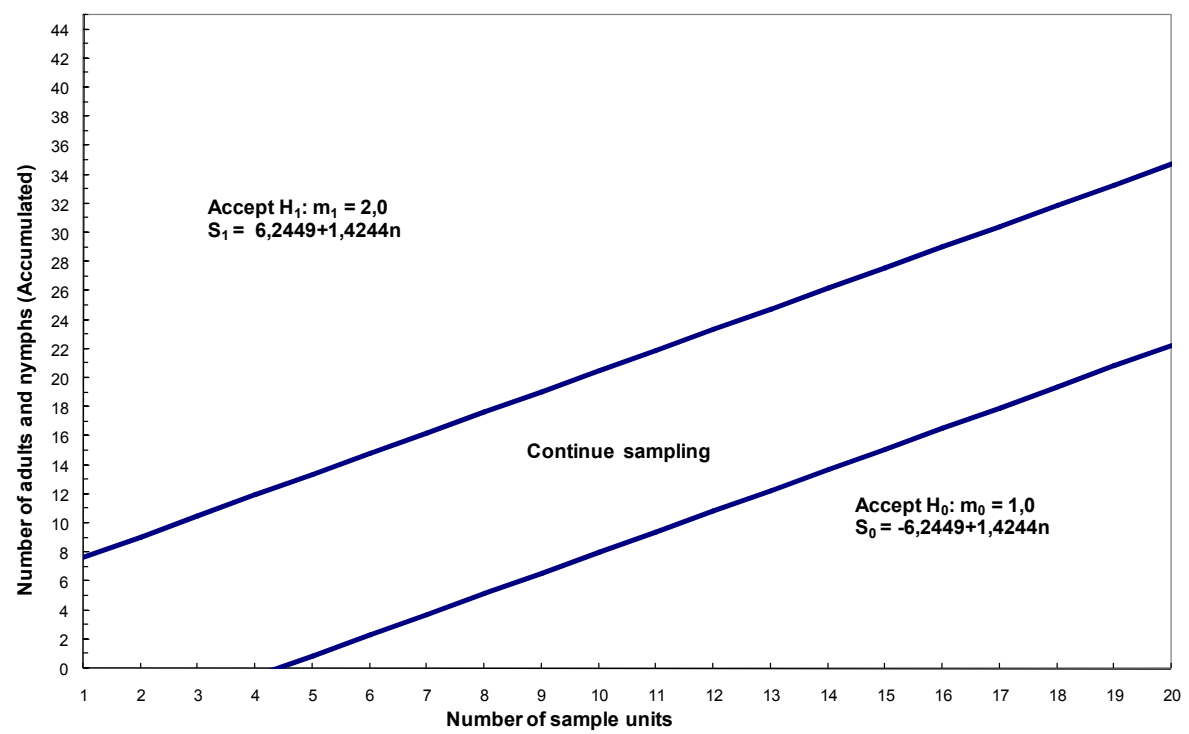

Figure 1. Decision lines of sequential sampling plan for the number of nymphs and adults of $E$. heros by beating cloth, based on the negative binomial distribution for Bt and non-Bt soybean

From the data provided by the equations of the upper and lower lines for use in field evaluations, a spreadsheet sample, which should be made as follows: the first observation made is noted in the field number of nymphs and adults per sample unit; The second observation is made and noted on field number of nymphs and adults per sample unit, and so on (Table 1). This number is accumulating after each sampling unit or cloth beat.

Table 1. Worksheet sequential sampling of adults and nymphs of $E$. heros for $\mathrm{Bt}$ and non-Bt soybeans

\begin{tabular}{|c|c|c|c|c|c|c|c|}
\hline $\begin{array}{l}\text { Number of } \\
\text { unit sample }\end{array}$ & $\begin{array}{l}\text { Lower limit } \\
\text { (Not } \\
\text { controlling) }\end{array}$ & $\begin{array}{c}\text { Number of } \\
\text { Nymphs and Adults } \\
\text { (Accumulated) }\end{array}$ & $\begin{array}{l}\text { Upper limit } \\
\text { (Control) }\end{array}$ & $\begin{array}{l}\text { Number of } \\
\text { unit sample }\end{array}$ & $\begin{array}{l}\text { Lower limit } \\
\text { (Not } \\
\text { controlling) }\end{array}$ & $\begin{array}{c}\text { Number of } \\
\text { Nymphs and Adults } \\
\text { (Accumulated) }\end{array}$ & $\begin{array}{l}\text { Upper limit } \\
\text { (Control) }\end{array}$ \\
\hline 1 & - & & 8 & 21 & 24 & & 36 \\
\hline 2 & - & & 9 & 22 & 25 & & 38 \\
\hline 3 & - & & 11 & 23 & 27 & & 39 \\
\hline 4 & - & & 12 & 24 & 28 & & 40 \\
\hline 5 & 1 & & 13 & 25 & 29 & & 42 \\
\hline 6 & 2 & & 15 & 26 & 31 & & 43 \\
\hline 7 & 4 & & 16 & 27 & 32 & & 45 \\
\hline 8 & 5 & & 18 & 28 & 34 & & 46 \\
\hline 9 & 7 & & 19 & 29 & 35 & & 48 \\
\hline 10 & 8 & & 20 & 30 & 36 & & 49 \\
\hline 11 & 9 & & 22 & 31 & 38 & & 50 \\
\hline 12 & 11 & & 23 & 32 & 39 & & 52 \\
\hline 13 & 12 & & 25 & 33 & 41 & & 53 \\
\hline 14 & 14 & & 26 & 34 & 42 & & 55 \\
\hline 15 & 15 & & 28 & 35 & 44 & & 56 \\
\hline 16 & 17 & & 29 & 36 & 45 & & 58 \\
\hline 17 & 18 & & 30 & 37 & 46 & & 59 \\
\hline 18 & 19 & & 32 & 38 & 48 & & 60 \\
\hline 19 & 21 & & 33 & 39 & 49 & & 62 \\
\hline 20 & 22 & & 35 & 40 & 51 & & 63 \\
\hline
\end{tabular}

Every culture needs a certain number of samples, depending on the pest and the stage of culture (Alatawi et al., 
2005). Although sampling is crucial for integrated protection of the decision is taken to control pests by farmers (Martins et al., 2010), consequence is spraying insecticides before they reach the level of control, increasing production costs and causing imbalance in agroecosystems (Martins et al., 2013).

Within the monitoring a cheaper option may be sequential sampling (Alatawi et al., 2005), which is characterized by the use of a variable number of sample units (Costa et al., 2007). Sequential sampling usually results in the observation of a smaller number of samples than would be required with conventional sampling (Fernandes et al., 2002), saving time and labor (Fernandes et al., 2003).

This procedure is repeated until the rule to terminate sampling is satisfied, namely: a) stop sampling the total number of bugs (adults and nymphs) counted equals or exceeds the upper limit, and if so, recommend the appropriate management the plague; or, b) stop sampling if the total insects counted is equal to or less than the lower limit, and if so, would not recommend control.

The operating characteristic curve of $\mathrm{CO}(\mathrm{m})$ for adults and nymphs of $E$. heros indicates the probability of making a correct decision for a given level of infestation. It was found that when the average is 1.0 test has a $95 \%$ chance of accepting $\mathrm{H} 0$ not recommended control, and when the average is 2.0 , the probability of accepting $\mathrm{H} 0$ is $5 \%$, that is, the probability of recommending control is $95 \%$ (Figure 2).

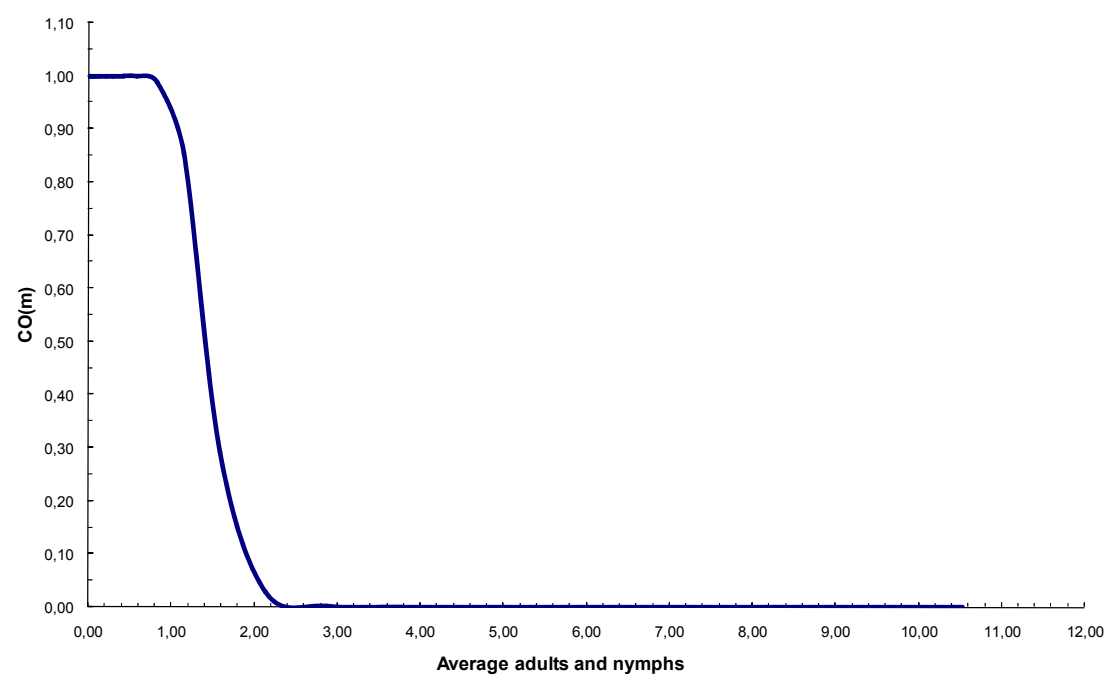

Figure 2. Operating Characteristic Curve $\mathrm{CO}(\mathrm{m})$ of the sampling plan for adults and nymphs of $E$. heros for $\mathrm{Bt}$ and non-Bt soybeans

And verified by the imaging function of the number of samples and the population average is eight sampling units, averaging 1.58 individuals and a peak of $16.72 \mathrm{E}$ (n) (Figure 3). For an average infestation of 2.0 bugs (adults and nymphs), indicated by the curve E (n) of the Sequential Probability Ratio Test of cloth beaten by Wald, the expected number of samples is nine (Figure 3). The sequential sampling plan, where the sample unit is examined, taking into account only if the individual is present or not, regardless of the number increases the ease and speed sampling (Farias et al., 2001). 


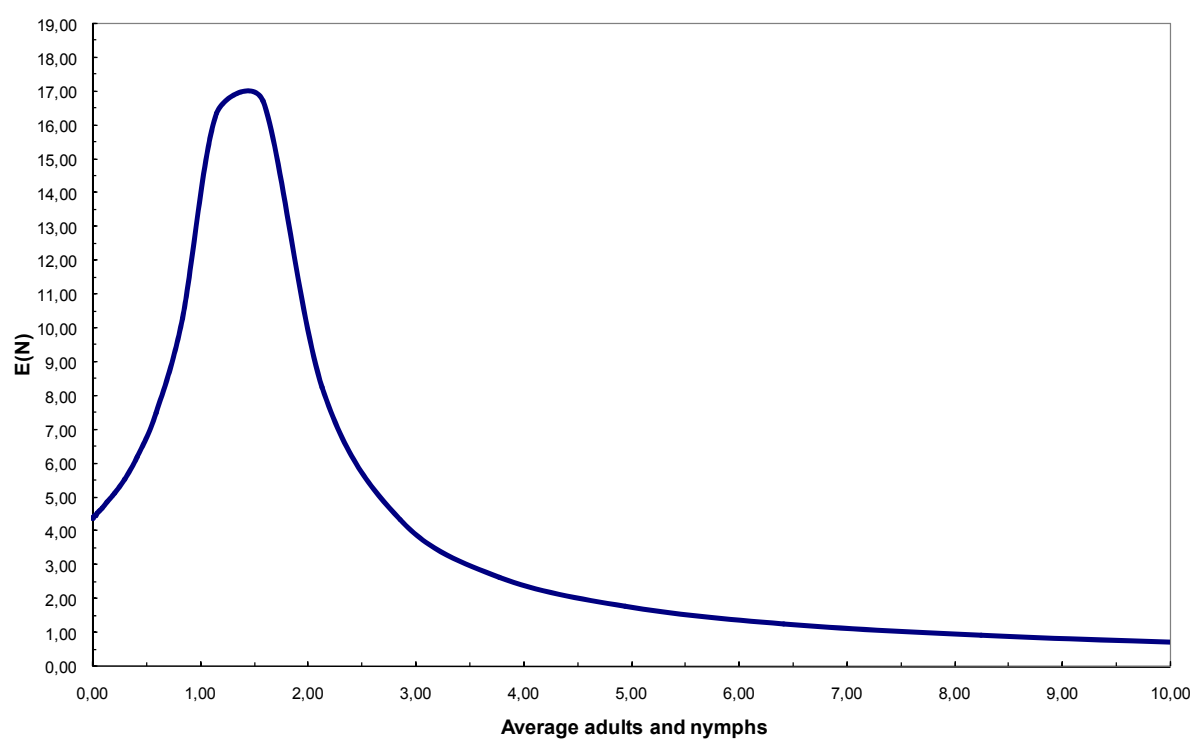

Figure 3. Curve of the expected size of samples of the sequential sampling plan for the number of adults and nymphs of $E$. heros by beating cloth, for Bt and non-Bt soybeans

\section{Conclusion}

For adults and nymphs of $E$. heros built a sequential sampling plan based on the negative binomial distribution, and the maximum expected number of sampling units to make the decision to control or not, is around eight.

For management based on economic injury level, the expected number of sample units is 17 , indicated by the Sequential Probability Ratio Test Wald curve.

\section{References}

Alatawi, F. J., Opit, G. P., Margolies, D. C., \& Nechols, J. R. (2005). Within-plant distribution of twospotted spider mites (Acari: Tetranychidae) on impatiens: Development of a presence-absence sampling plan. J. Econ. Entomol., 98, 1040-1047. http://dx.doi.org/10.1603/0022-0493-98.3.1040

Barbosa, J. C. (1992). A amostragem seqüencial. In O. A. Fernandes, A. C. B. Correia \& S. A. Bortoli de (Eds.), Manejo integrado de pragas e nematóides (p. 253). Jaboticabal, FUNEP.

Barros, R., \& Degrande, P. E. (2012). Desempenho do algodão-Bt como tática de controle de pragas em condições de campo. Cientifica, 40, 117-137.

Bliss, C. I., \& Owen, A. R. G. (1958). Negative binomial distribution with a common K. Biometrika, 45, 37-58. http://dx.doi.org/10.1093/biomet/45.1-2.37

Costa, M. G., Barbosa, J. C., \& Yamamoto, P. T. (2007). Planos de amostragem seqüenciais para Orthezia praelonga Douglas (Hemiptera, Sternorrhyn-cha: Ortheziidae) na cultura de citros. Neotrop. Entomol., 36, 932-938. http://dx.doi.org/10.1590/S1519-566X2007000600016

Dutra, C. C., Meotti, C., Fernandes, M. G., \& Raizer, J. (2012). Riqueza e composição de espécies de insetos visitantes florais de algodoeiro Bt e não-Bt. Arq. Inst. Biol., 79, 353-361.

Farias, P. R. S., Barbosa, J. C., \& Busoli, A. C. (2001). Amostragem seqüencial (presenca-ausência) para Spodoptera frugiperda (J. E. Smith) (Lepidoptera: Noctuidae) na cultura do milho. Neotrop. Entomol., 30, 691-695. http://dx.doi.org/10.1590/S1519-566X2001000400026

Fernandes, M. G., Busoli, A. C., \& Barbosa, J. C. (2002). Amostragem seqüencial de Spodoptera frugiperda (J. E. Smith, 1797) (Lepidoptera, Noctuidae) em algodoeiro. Rev. Bras. Agrocienc., 8, 213-218.

Fernandes, M. G., Busoli, A. C., \& Barbosa, J. C. (2003). Distribuição espacial de Alabama argillacea (Hübner) (Lepidoptera: Noctuidae) em algodoeiro. Neotrop. Entomol., 32, 107-115. http://dx.doi.org/10.1590/S1519-566X2003000100016

Fernandes, M. G., Spessoto, R. R., Degrande, P. E., Rodrigues, T. R., \& Herzog, T. R. R. (2011). Sequential sampling of Aphis gossypii Glover (Hemiptera: Aphididae) and Frankliniella schultzei Trybom 
(Thysanoptera: Thripidae) on cotton crop. Neotrop. Entomol., 40,258-263. http://dx.doi.org/10.1590/S1519-566X2011000200016

Fietz, C. R., \& Fisch, G. F. (2006). O clima da região de Dourados, MS (1st ed., p. 32). Dourados, MS, Brasil: Embrapa Agropecuária Oeste. (Documentos, 85).

Fonseca, P. R. B., Fernandes, M. G., Justiniano, W., Cavada, L. H., \& Silva, J. A. N. (2013). Leaf Chlorophyll Content and Agronomic Performance of Bt and Non-Bt Soybean. J. Agric. Sci., 5, 117-125.

Fonseca, P. R. B., Fernandes, M. G., Justiniano, W., Cavada, L. H., \& Silva, J. A. N. (2014). Spatial Distribution of Adults and Nymphs of Euschistus heros (F.) (Hemiptera: Pentatomidae) on Bt and Non-Bt Soybean. $J$. Agric. Sci., 6, 1-12.

Hoffmann-Campo, C. B., Moscardi, F., CorrÊA-Ferreira, B. S., Oliveira, L. J., Sosa-Gómez, D. R., Panizzi, A. R., ... Oliveira, E. B. (2000). Pragas da soja no Brasil e seu manejo integrado (p. 70). Londrina: Embrapa Soja (Circular Técnica, 30).

Kaplan, I., \& Eubanks, M. D. (2002). Disruption of cotton aphid (Homoptera: Aphididae) - natural enemy dynamics by red imported fire ants (Hymenoptera: Formicidae). Environ. Entomol., 131, 1175-1183. http://dx.doi.org/10.1603/0046-225X-31.6.1175

Kogan, M., \& Herzog, D. C. (1980). Sampling methods in soybean entomology (p. 587). New York, Springer-Verlag. http://dx.doi.org/10.1007/978-1-4612-9998-1

Krinski, D., Favetti, B. M., Lima, A. G., \& Brum, T. R. (2013). Oviposition preference of the neotropical brown stink bug Euschistus heros on artificial substrates of different colors. Cienc. Rural, 43, 2185-2190. http://dx.doi.org/10.1590/S0103-84782013001200011

Kuno, E. (1981). Sampling and analysis of insect populations Annu. Rev. Entomol., 36, $285-304$. http://dx.doi.org/10.1146/annurev.en.36.010191.001441

Martins, G. L. M., Vieira, M. R., \& Barbosa, J. C. (2013). Sequential Sampling Plan for Tenuipalpus heveae Baker (Acari: Tenuipalpidae) on Rubber Tree. Neotrop. Entomol., 42, $200-204$. http://dx.doi.org/10.1007/s13744-012-0105-1

Martins, G. L. M., Vieira, M. R., Barbosa, J. C., Dini, T., Manzano, A. M., Alves, B. M. S., \& Silva, R. M. (2010). Distribuição espacial de Tenuipalpus heveae Baker (Acari: Tenuipalpidae) na cultura da seringueira. Neotrop Entomol., 39, 703-708. http://dx.doi.org/10.1590/S1519-566X2010000500005

Panizzi, A. R., Bueno, A. F., \& Silva, F. A. C. (2012). Insetos que atacam vagens e grãos. In C. B. Hoffman-Campo, B. S. Corrêa-Ferreira \& F. Moscardi (Eds.), Soja: Manejo Integrado de Insetos e outros Artrópodes-Praga (1st ed., p. 420). Brasília, DF: Embrapa.

Qaim, M., \& Zilberman, D. (2003). Yield effects of genetically modified crops in developing countries. Science, 299, 900-902. http://dx.doi.org/10.1126/science.1080609

Rodrigues, T. R., Fernandes, M. G., \& Santos, H. R. (2010). Distribuição espacial de Aphis gossypii (Glover) (Hemiptera, Aphididae) e Bemisia tabaci (Gennadius) biótipo B (Hemiptera, Aleyrodidae) em algodoeiro Bt e não-Bt. Rev. Bras. Entomol., 54, 136-143. http://dx.doi.org/10.1590/S0085-56262010000100019

Sturmer, G. R., Cargnelutti Filho, A., Stefanelo, L. S., \& Guedes, J. V. C. (2012). Eficiência de métodos de amostragem de lagartas e de percevejos na cultura de soja. Ciência Rural, 42, $2105-2111$. http://dx.doi.org/10.1590/S0103-84782012005000145

Vivan, L. M., \& Degrande, P. E. (2011). Pragas da soja. In: Boletim de pesquisa de soja (1st ed., p. 297). Rondonópolis: Fundação MT. (Boletim, 15).

Wald, A. (1947). Sequential analysis (p. 212). New York, John Wiley \& Sons.

Young, L. J., \& Young, J. H. (1998). Statistical ecology: A population perspective (1st ed., p. 565). Boston: Kluwer Academic Publishers. http://dx.doi.org/10.1007/978-1-4757-2829-3

Yu, H. L., Yun, H. L., \& Kong, M. W. (2011). Risk assessment and ecological effects of transgenic Bacillus thuringiensis crops on non-target organisms. Journal of Integrative Plant Biology, 53, 520-538. http://dx.doi.org/10.1111/j.1744-7909.2011.01047.x

Zambiazzi, E. V., De Nadai, J., Guilherme, S. R., \& Bonaldo, S. M. (2012). Controle biológico in-vitro do percevejo-marrom (Euschistus heros) com Beauveria bassiana. Rev. Trop. Cienc. Agr. Biol., 6, 44-48. 


\section{Copyrights}

Copyright for this article is retained by the author(s), with first publication rights granted to the journal.

This is an open-access article distributed under the terms and conditions of the Creative Commons Attribution license (http://creativecommons.org/licenses/by/3.0/). 